\title{
Exchange Rate Regime, Inflation Targeting and Macroeconomic Performance
}

\author{
Houda Jendoubi El Achnab ${ }^{1}$ \\ ${ }^{1}$ Faculty of Economics and Management of Tunis, Tunisia \\ Correspondence: Houda Jendoubi El Achnab, Higher School of Economic and Commercial Sciences, Tunis, \\ Tunisia. Tel: 216-9747-7744. E-mail: houda_jen@yahoo.fr
}

Received: May 11, 2016

doi:10.5539/ijef.v8n8p143
Accepted: June 6, 2016

Online Published: July 25, 2016

URL: http://dx.doi.org/10.5539/ijef.v8n8p143

\begin{abstract}
This study aims to examine whether emerging countries can use both an inflation targeting strategy and exchange rate regime targeting in order to improve their macroeconomic performance. Empirically, we are based on a sample of 28 emerging countries, over the period 1985-2000. Our findings yielded from mean comparisons tests reveal that in addition to the inflation targeting strategy, countries may adopt an exchange rate regime to improve their growth and decrease their inflation. Moreover, the use of interactive variables in panel models shows that the inflation targeting strategy is a complement to the flexible exchange-rate regime and a substitute for the fixed exchange rate regime.
\end{abstract}

Keywords: exchange rate regime, targeting inflation strategy, growth, inflation

\section{Introduction}

The mastery of inflation is the chore objective of the monetary authorities, since a high inflation level is a threat to macroeconomic stability, which hinders growth and distorts the decision-making process of the various economic agents.

To this end, the monetary authorities propose various strategies or a combination of monetary strategies to sort out the issue of the inflation such as the choice of an appropriate exchange rate regime, inflation targeting or the monetary aggregate targeting.

The year (1990) witnessed severe currency- crises such as that of Mexico in 1994, southeast Asia in 1997, brazil in 1999, Ecuador in 1999, turkey in 2001 and Argentina in 2002; the main cause was the adoption of an inappropriate exchange rate regime, in a context of financial openness and high capital mobility. Henceforth, to cope with this situation, the monetary authorities decided to offer more flexibility on the exchange rate regime (Note 1). Most emerging countries adopted the flexibility of their regimes including those adopting an inflation targeting policy. These countries are thus a combination of flexible regime and inflation targeting scheme. They are therefore in the process of combining two monetary policies.

The new combination of these two strategies of monetary inflation targeting and exchange rate regime was the subject matter of a lively debate both on potential risks and on the merits of this strategy. Academically, the theoretical and empirical literature on this issue is still unknown, given the too small number of advocates of this new strategy. Some studies (Bernanke \& Meshkin, 1997; Mohanty \& Klau, 2004, 2005; Edwards, 2006; Pavasthipaisit, 2010; Pourroy, 2012; Ostry et al., 2012; Anderson et al., 2014) show that the countries that adopt a monetary policy strategy combining inflation targeting and exchange rate regime achieved the best macroeconomic performance in terms of inflation and growth than the other countries adopting a single currency regime. Thus, it is necessary to enhance the complementary relationship between these two monetary policies.

Unlike these studies, others carried out by (Mishkin \& Schmid-Hebbel, 2002; Mccallum, 2006; Aizenman et al., 2011; Garcia et al., 2011; Whelan, 2013) did not lead to a clear relationship between the inflation- targeting strategy and the exchange- rate regime strategy. For this purpose, it is necessary to establish a substitutability relationship between the latter.

Moreover, it is noteworthy that all these deductions cannot be generalized given the fact that they are strongly-linked to the sample used, to the selected study-period as well as to the implemented econometric methodology. Given the relevance of the matter and to reveal these ambiguities, it seemed useful and 
constructive to focus on the study of this new framework for conducting a monetary policy, based on a combination of inflation targeting and targeting the exchange rate regime.

Also, as far as the inflation-targeting economies are concerned, we have to find out whether the adoption of an exchange rate regime is conflicted or not with the inflation targeting strategy in achieving the main goal of minimizing inflation? Or is it that the adoption of the exchange rate regime and inflation creates a favorable economic stability?

The aim of this work is to examine whether the emerging countries targeting a level of inflation adopt at the same time a specific exchange rate regime in their monetary strategy. In other words, in this work we will examine the possible links between the monetary strategies namely inflation targeting and the targeting of an exchange rate regime.

Thus, in this work, we contribute to the currently-available literature through several axes. The first is to study the case of emerging economies bearing specific features. These are countries adopting modernization and openness to international trade strategies, experiencing high inflation rate- episodes and having weak monetary institutions. These countries always seek an effective monetary policy ensuring aiming at achieving a macroeconomic stability.

The second axis is to take a broader study era that covers the period from 1985 to 2008; this guarantees a large study base that allows us to follow the different monetary policies of both emerging inflation targeters and non-inflation targeters. Also, this period covers all the dates of adoption of inflation targeting for the sample countries.

The third priority is to integrate other economic variables strongly linked to inflation, growth, the exchange rate regime of inflation targeting and the combination of these. The fourth goal is to consider the 1999 IMF official classification in (de facto) that is clearer than the classification (de jure) which is carried out on the simple declaration of the member countries.

This work is organized as follows. In the first section, we explicit our literature review. The second section is devoted to the empirical methodology. The third section provides our empirical results and the last section concludes our paper.

\section{Literature Review}

In the last two decades, the subject of the effect of the adoption of a regime change strategy or inflation targeting strategy has been the subject of an intense current debate. In this context some economists have focused on the benefits of adopting an exchange rate regime in a context of inflation targeting strategy. They have attempted to examine the macroeconomic performance achieved from the simultaneous adoption of an inflation targeting strategy and an exchange rate regime strategy. To do so, they resorted to a comparison of the effectiveness of the different strategies with or without a monetary exchange strategy adoption.

Here underneath, we present the empirical studies that have shown the beneficial effects in terms of macroeconomic performance of the adoption of a combined strategy between inflation targeting and exchange rate regime.

According to the theoretical studies conducted by Bernanke and Mishkin (1997), it appears that it is best to accompany the inflation targeting strategy by floating exchange rate strategies, which helps the countries adopting this system to cope with economic shocks and the debate between these two inflation targets will be our priority.

Mohanty and Klau (2004) and (2005) show that 11 emerging countries adopting inflation targeting countries among which 2 countries do not react to the changes in the exchange rate regime, because of fear of floating; hence, concluded that the strategy of inflation targeting has affected the behavior of the central banks to their strong concerns with respect to the adopted exchange rate regime.

Edwards (2006) studied the monetary policy for 13 emerging and transition economies and has scored only 11 cases of these countries, the exchange targeting is very important.

Mello and Moccero (2007) surveyed the case of Latin American countries. These studies in Brazil and Chile, the adoption of inflation targeting was combined with an exchange rate policy to minimize inflation, while in Mexico and Colombia the relationship is unclear.

Pavasthipaisit (2010) emphasized the importance attached to the exchange rate policy in the case of a strong integration with the international financial capital market. Pourroy (2012) examined theoretically and empirically to what extent the exchange had guaranteed for the emerging countries adopting inflation targeting, and which achieved a good macroeconomic performance during 2007-2008 period, to 16 emerging adopting inflation targeting, among which 9 countries let their currency régimes float freely. Then, he uses the dif in dif method for 
making comparisons in terms of averages of the macroeconomic performance between them. He deduced that the countries adopting inflation targeting and which have paid a particular attention to the exchange rate regime have accomplished a better macroeconomic performance than other country groups adopting only a flexible regime. He deduced that the rate of inflation was the lowest in the economies in targeting their exchange rate regime. However, these countries have been more successful in anchoring inflation expectations on their target than the countries targeting the floating exchange rate regime.

Ostry et al. (2012) are interested in the study of 14 emerging inflation - targeters during the date of adoption of inflation targeting each country until the year 2010 .they pointed out that the exchange rate policy attaches a great importance to the inflation targeting policy in the conduct of their monetary policies. Anderson (2014) studied whether the flexible exchange rate regime with an inflation target provides benefits in terms of growth in the 2007-2012 crises and withstands them better than other currency regimes. They concluded that inflation targeting is better for growth than other regimes, including the flexible regime. In the OECD countries, a part of this performance is attributed to the flexibility of the exchange rate regime targeting countries. The analysis covers more than 100 countries for a random effect panel that reveals a positive relationship between inflation and growth targeting.

Unlike these studies, others have not led to a clear relationship between the inflation targeting strategy and the exchange rate regime strategy. In this respect, we mention the work of Mishkin and Schmid-Hebbel (2002) which show that the adoption of inflation targeting in emerging countries, generates a considerable macroeconomic performance but the positive effect is due to the structural specificities of these countries. Mccallum (2006) compared the macroeconomic performance between the different monetary strategies and has resulted in the absence of a relationship between inflation targeting and the targeting of exchange. Azenman et al. (2011) show that non-targeting inflation countries are more attached than the inflation targeting economies, to the exchange rate regime.

Garcia et al. (2011) conducted performance comparisons among the different monetary policies from two samples of developed and emerging countries. They deduced that there is no relationship between these different strategies.

Whelan (2013) argues that the countries that target both inflation and floating rates have been subject to much criticism during the crisis period, as inflation targeting ignores the objective of financial stability starting from the minimization of inflation as they are more focused on the consumption price. However, Gallego and Jones (2005) theoretically show that the fear of floating is the most efficient choice of other strategies in emerging countries.

\section{Empirical Methodology}

\subsection{Sample Selection}

We seek to highlight the macroeconomic effects of the adoption of a combination of an inflation strategy and the choice of an appropriate exchange rate regime for 28 emerging countries that are distributed as follows:

- 11 countries adopting inflation targeting: Brazil, Columbia, Hungary, Mexico, Peru, Philippines, Poland, South Africa, Thailand, Czech Republic and Turkey.

- 17 countries not adopting inflation targeting: Argentina, Botswana, Bolivia, Bulgaria, Costa Rica, Ivory Coast, Dominican republic, Ecuador, el Salvador, Egypt, India, Malysia, Morocco, Pakistan, Tunisia, Uruguay and Venezuela.

The study covers the period from1985 to 2008. All the data used in this section are extracted from the annual publication of the World Bank (WDI-2012) and the international monetary fund (IMF).

Regarding the variables related to the exchange rate regime choice, we will adopt the official classification de facto IMF (2002/2008) from the IMF annual report (Exchange Agreement and Exchange Restriction) and from the classification of Reinhart and Rogoff (2004). This classification generates eight (Note 2) headings as fisher (2001) grouped them as follows: the first three schemes are fixed, the three second ones are intermediate and the last two are flexible regime.

\section{Econometric Approach}

Our econometric approach consists of two basic stages. The first examines whether the countries that target inflation levels lean towards a particular exchange rate regime to improve their macroeconomic performance in this case an increase in growth and inflation curb. More specifically, our sample will be split into two sub samples: countries adopting inflation targeting strategy and countries not adopting an inflation targeting strategy. 
They make up a control sample. Then, for each sub-sample we build (03) groups: G1 the countries adopting a fixed exchange rate regime; $\mathrm{G} 2$ the countries adopting a flexible exchange rate regime and $\mathrm{G} 3$ the countries adopting an intermediate exchange rate regime.

It should be noted that we shall proceed in the same way for the control sample and get three subgroups: G4 the countries choosing a fixed exchange rate regime; G5 the countries choosing a flexible exchange rate regime and G6 the countries choosing the exchange rate regime intermediate. For this step, all comments will be treated as independent observations as we strive to identify the links between the exchange rate regime and inflation targeting abstraction realized by the inter-temporal relations.

Finally, average-comparison tests will be made to detect if in addition to the inflation targeting strategy, countries still adopt a specific exchange rate regime to improve their macroeconomic performance. Thus, a comparison of means tests will be carried out between the G1 and G4, G2 and G3 and G5 and G6 groups.

To compare the growth levels and inflation between groups G1 and G4, G2 and G3 and G5 and G6, we rely on the non-parametric Wilcoxon test.

The second step of our empirical study tries to find out if an inflation targeting strategy is a complement or a substitute for the adequate exchange rate regime. In this regard, we employ two models of interactive variables. The interaction will be between the exchange rate regime and inflation targeting strategy. These two models are presented as follows:

$$
\left\{\begin{array}{l}
\pi_{i t}=\alpha+\alpha_{1} E X R_{i t}+\alpha_{2} C I+\alpha_{3} V C I N F_{i t}+\alpha_{4}\left(E X R_{i t} * C I\right)+\varepsilon_{i t} \quad(\text { Model 1) } \\
T C G R T_{i t}=\alpha+\alpha_{1} E X R_{i t}+\alpha_{2} C I+\alpha_{3} V C G R T_{i t}+\alpha_{4}\left(E X R_{i t} * C I\right)+\varepsilon_{i t} \quad \text { (Model 2) }
\end{array}\right.
$$

with:

$-\pi_{i t}$ : the level of inflation in a country (i) in year (t);

-TC GRT $i t$ : gross domestic product per capita growth rate of the country (i) at time (t);

$-\alpha$ : constant;

$-\mathrm{EXR}_{\mathrm{it}}$ : the binary variable that indicates the exchange rate regime adopted for a country (i); in year(t), this variable is set to rise to 1 , if the adopted scheme is fixed and 0 otherwise;

$-C I$ : inflation targeting (dummy variable): which takes the value (1) if the country adopts inflation targeting and (0) if not;

$-\alpha_{2}$ : coefficient of the dummy variable that measures the real effect of inflation targeting; respectively, on the level of inflation in model (1) and the level of growth in model (2);

$-V C I N F_{i t}$ : inflation control variable, it includes:

$-G D P_{i t}:$ gdp growth rate per capita for country (i) in year (t);

$-\mathrm{TRD}_{\mathrm{it}}$ : the degree of openness to international trade "trade" for country (i) in the year (t);

$-V C G R T_{i t}$ : growth control variable that includes:

- the rate of investment (capital formation)

- the degree of openness to international trade (trade)

- the accumulation of knowledge (research)

- the variable stock of physical capital (gdp capita)

- the stock of human capital (education)

- the rate of inflation (inflation)

- the role of the state (debt)

- degree of financial development (domestic credit)

- $\left(E X R_{i t} * C I\right)$ : the dummy variable describes the simultaneous adoption of an inflation targeting policy and a currency strategy.

$-\alpha_{4}=$ the coefficient for the dummy variable that captures the real effect of the combined adoption of an inflation targeting and exchange rate regimes respectively on the level of inflation in (model 1) and growth in (model 2).

- $\varepsilon_{\mathrm{it}}$ : error term $\mathrm{i}=$ country index and $\mathrm{t}$ time. 


\subsection{Variable Measurement}

We examine the combined effect of the adoption of inflation targeting and the exchange rate regime of targeting on the macroeconomic performance, namely the level of inflation and the level of growth starting from two interactive-variable models among which the variables to be explained are: the level of inflation and the growth level. The explanatory variables encompass binary variables related to the exchange rate regime, the inflation targeting and interaction strategy between inflation targeting and the exchange rate regime on the one hand.

And the control vectors for inflation and growth on the other hand.

These control vectors include several key economic variables that are essential both for the effectiveness of inflation targeting, the exchange rate regime and the interactive combinations of the latter.

These vectors also include the control variables in this case the gdp growth rate and the degree of openness to international trade for inflation and the degree of openness to international trade, the growth rate, accumulation knowledge, the variable stock of physical capital, the stock of human capital, the inflation rate, the role of the state and the degree of financial development for growth.

\section{Empirical Results}

We start the presentation of our empirical results preceded by a descriptive statistics of our variables.

\subsection{The Relationship between Inflation Targeting, and Regime Change through Macroeconomic Performance Graphics}

Figure 1 shows the level of inflation and growth for the inflation- targeting and non-targeting countries and countries adopting different exchange rate regimes.

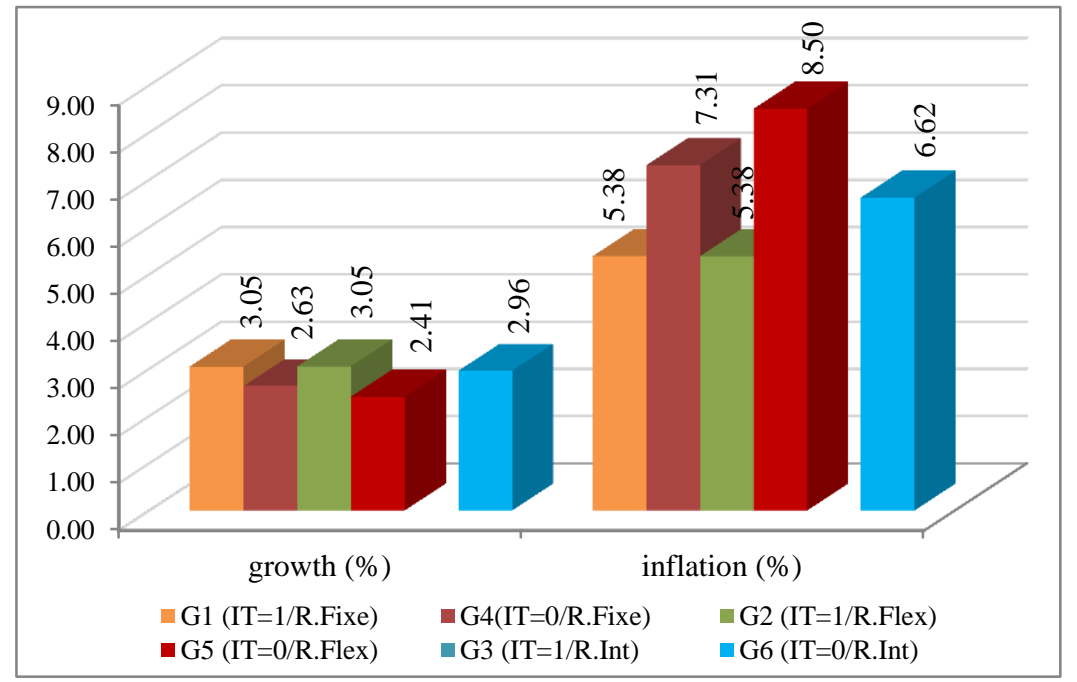

Figure 1. Level of inflation and growth for the targeting countries and not targeting countries adopting different exchange rate regimes

The graph shows that the countries targeting their inflation level and adopting a fixed regime (G1 group) show an average of $3.0470 \%$ and an average inflation level of $5.3834 \%$. Similarly, the countries not adopting the targeting and using the same fixed exchange regime (G4 group) achieve a $2.6312 \%$ growth and an inflation rate of $7.3071 \%$. This shows that a fixed system does not improve growth and inflation for the targeted countries.

The countries targeting their level of inflation and at the same time adopting a flexible exchange rate regime (G2 group) generate an average of $3.7491 \%$ and an inflation level of $5.3201 \%$. By comparison to the countries not adopting targeting and using the same exchange rate flexibility (G5 group), we find that their average growth rate is $2.4107 \%$ and the inflation rate is $8.5019 \%$. Such a result indicates that the adoption of a flexible regime accompanied with an inflation targeting strategy allows the emerging countries to improve their macroeconomic performance. Therefore, such a finding reveals that a growing complementary relationship seems to occur between an inflation targeting strategy and a flexible exchange rate regime.

It should be noted that the countries adopting an intermediate exchange rate regime are not using an inflation targeting strategy (G3 group and G6). In other words, the emerging countries do not use both an intermediate exchange rate regime and an inflation targeting strategy, leading us to consider the possibility of the existence of 
substitutability relationship between an intermediate exchange rate regime and inflation targeting strategy.

We should also bear in mind that the names of the inflation- targeting and non-targeting countries and focus on their inflation and growth levels. The goal is always to detect the possibilities of the existence of links between the exchange rate regime, the inflation targeting strategy and the approximated macroeconomic performance, the average growth (Note 3 ) and the average inflation rate, (Figure 2 shows these relationships).

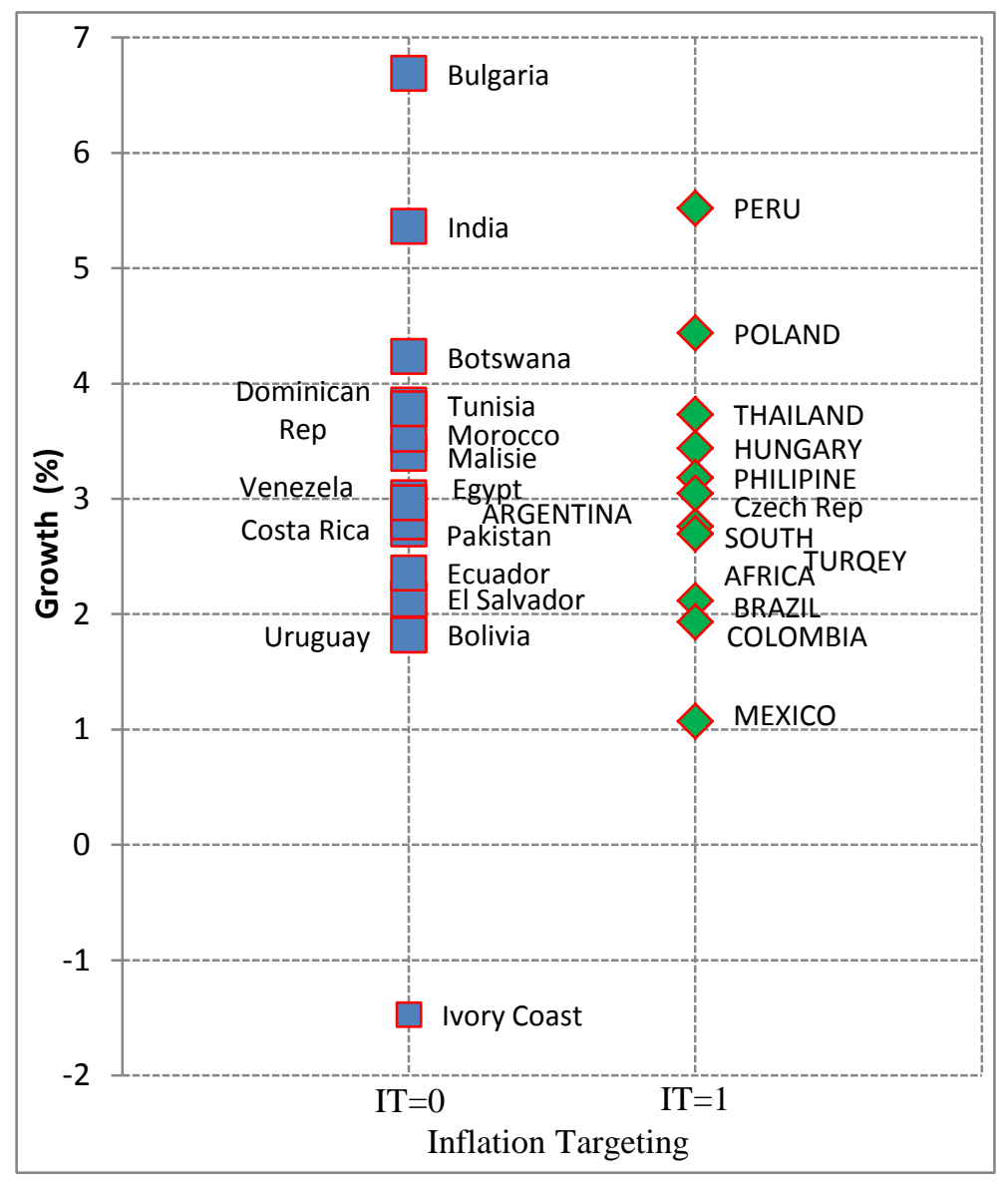

Figure 2. Level of average growth of the countries targeted and not targeted in our sample

The graph shows that the non-targeting countries show growth levels in the range $[-1.47 ; 6.68]$. The lowest level of growth is recorded by Ivory Coast, while the highest level is reached by Bulgaria. Alongside the targeted countries, we see that growth belongs to interval $[1.07 ; 5.52]$, the lowest level of growth for these countries is posted by Mexico while the highest is achieved in Peru. From this graph we can infer that the inflation targeting strategy has a favorable effect on growth since the interval is greater than that of non-targeting countries.

We also seek to find out the links between the inflation targeting strategy and the macroeconomic performance approximated by the average inflation (Note 4). Figure 3.displays these links. 


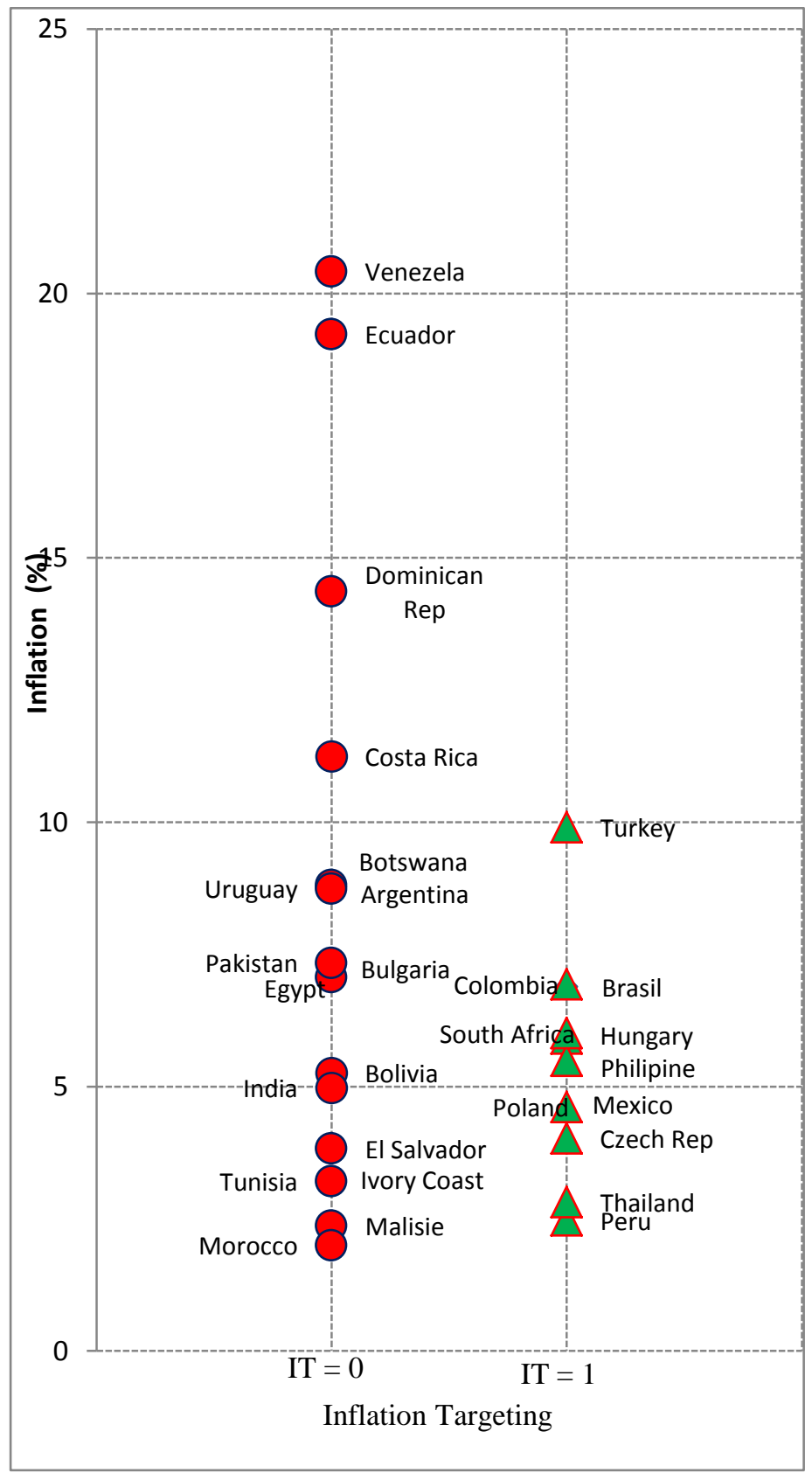

Figure 3. Average inflation for targeting and not targeting countries in our sample

The graph shows that the non-targeting countries show levels of inflation in the range [2.0;20]. The lowest level of inflation is recorded by morocco while the highest level is reached by Venezuela. As for the targeting countries, it appears that their average inflation belongs to the interval [2.47; 9.9] .the lowest level of inflation for these countries is posted by Peru while the highest is reached by turkey. From this graph we can infer that the inflation targeting strategy has a favorable impact on inflation since the gap is less than that of the non-targeting countries.

5.2 Links between Inflation Targeting, Regime Change and Macroeconomic Performance through Medium Tests Comparisons

In Table 1 are displayed the inflation and growth means for the targeting and non-targeting countries under different exchange rate regimes. In other words, we provide the means for the 6 groups we identified in our econometric approach. The table also provides the dates of the adoption of targeting for each country. It also provides the names of the targeting and non- countries: 
Table 1. Tests of comparison of averages growth and inflation for groups classified by the simultaneous targeting of their inflation and exchange rate regime

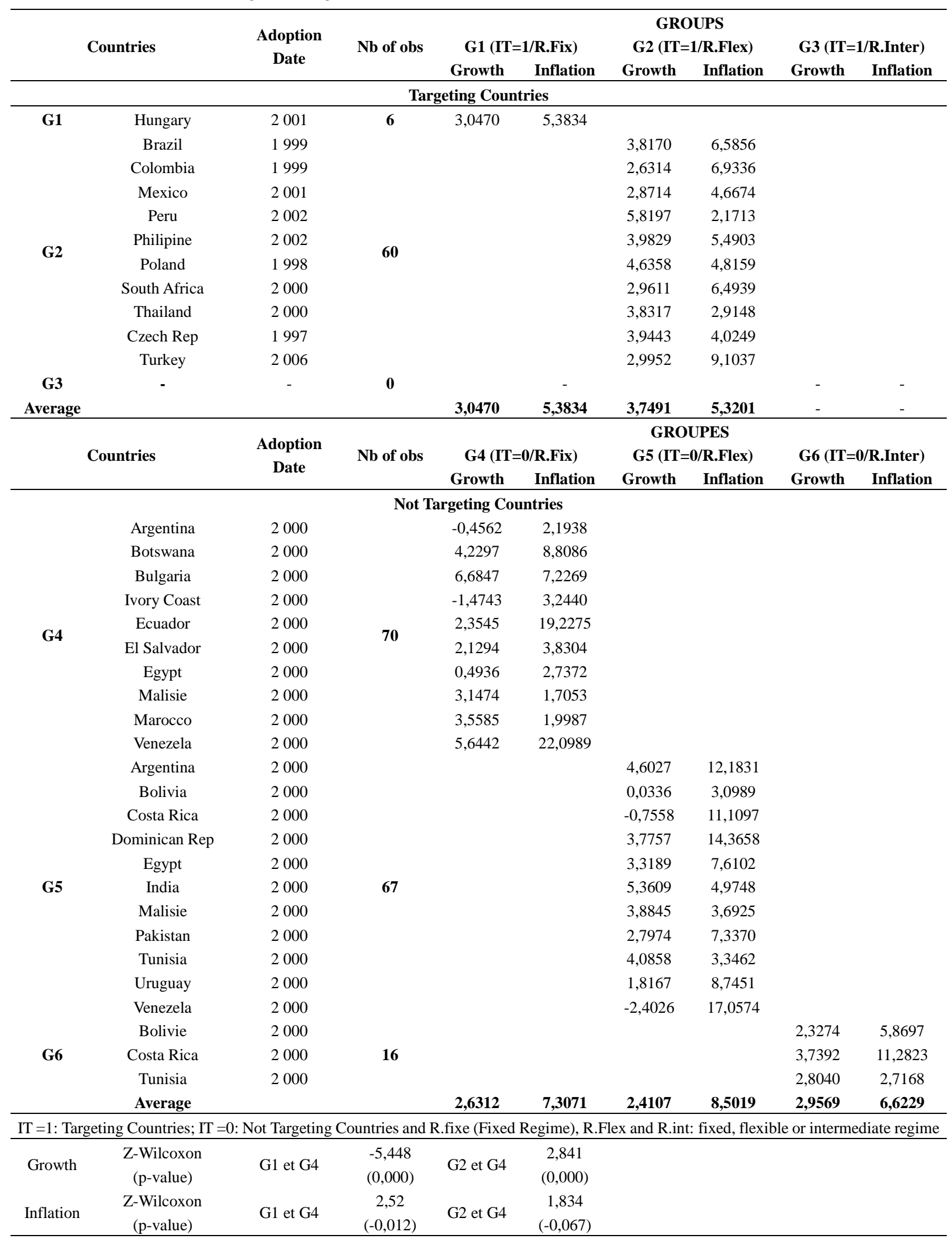

In Table 1, we find that the majority of countries targeting their level of inflation belong to flexible regime. in other words, they are the countries belonging to group g2. if we try the following comparison in terms of growth and inflation between the two monetary policies namely inflation targeting and exchange rates, it appears that 
only the combination of inflation targeting and flexible exchange rate regime allows the increase of growth and inflation minimizing. Thus, the simultaneous adoption of inflation targeting with flexible exchange rate regime achieves the best performance in terms of average inflation level (5.3211\%: the lowest level) and average growth (3.7491\%: the highest level of growth).

For countries targeting inflation and not only adopting an exchange rate policy, it turns out that there is no dominance of a particular exchange rate regime such as the case of targeting countries. Indeed, we find 70 cases with a fixed regime, 67 observations with a flexible regime and 16 with an intermediate regime. However, although the majority of countries lean towards a regime of fixed or flexible exchange at the expense of the middle or intermediary exchange rate regime, we notice that the intermediate regime allows the emerging countries to record an average growth rate that is higher (2.956\%) and an inflation level that is lower $(6.6229 \%)$.

It should be noted that group g1 is composed of several observations but belongs to the same country which is Hungary. His country adopts an inflation targeting strategy with a fixed exchange rate regime. Besides, it is the only country that has almost kept the same scheme during the study-period with some fluctuations only to the flexible regime. However, with this fixed regime, this country managed to control its average inflation level at $5.383 \%$ and achieved an average growth of $3047 \%$.

\subsection{Links between Inflation Targeting and Exchange Regime through Macroeconomic Performance Models}

The following table presents the results of the estimation models we have presented earlier in our econometric approach. The estimation of the two interactive- variables models was made for the whole sample. We also note that each model was estimated for three groups: model (1): countries adopting the intermediate-flexible regime; model (2): the countries adopting the fixed-flexible regime model (3): the countries adopting the fixed-intermediate regime.

The fact of considering the two exchange rate regimes simultaneously allows us to avoid the problem of endogeneity.

Since an improved macroeconomic performance means a reduction in inflation and an increase in growth, it is legitimate to carry out two independent estimates for each variable: endogenous growth and inflation.

\subsubsection{Links between Inflation Targeting, Exchange Regime and Growth}

The following table provides the results of the estimation for the case where the dependent variable is growth.

Table 2. Results of the estimation of the effect of the simultaneous adoption of an inflation targeting strategy and exchange on growth

\begin{tabular}{|c|c|c|c|c|c|c|}
\hline \multirow[t]{2}{*}{ gdpgrowth } & \multicolumn{2}{|c|}{ Intermediate-flexible (model 1) } & \multicolumn{2}{|c|}{ Fixed-flexible (model 2) } & \multicolumn{2}{|c|}{ Fixed-intermediate (model 3) } \\
\hline & Coefficient & Tstudent & Coeff & Tdestudent & Coeff & Tdestudent \\
\hline Intermediate & -0.11738 & $(-0.09)^{* *}$ & - & - & -0.1623 & $-0.12 *$ \\
\hline Flexible & 0.044946 & $(0.06)^{* *}$ & -0.1623 & $-0.12 *$ & - & - \\
\hline Fixed & - & - & 0.11738 & $0.09 * *$ & -0.0449 & $-0.06 * * *$ \\
\hline Investment & 0.30249 & $5.55^{* * * *}$ & 0.30249 & $5.55 * * *$ & 0.30249 & $5.55^{* * *}$ \\
\hline Openess & -0.00336 & $-0.20 *$ & -0.00336 & $-0.20 *$ & -0.00336 & $-0.20 *$ \\
\hline Knowlege & 0.0000449 & $0.30 *$ & 0.0000449 & $0.30 *$ & 0.0000449 & $0.30 *$ \\
\hline Physical capital & 0.00077 & $2.15^{* * *}$ & 0.00077 & $2.15^{* * *}$ & 0.00077 & $2.15^{* * *}$ \\
\hline Eductaion & 4.345 & $3.84 * * *$ & 4.345 & $3.84 * * *$ & 4.345 & $3.84 * * *$ \\
\hline Inflation & -0.26719 & $-8.19 * * *$ & -0.26719 & $-8.19 * * *$ & -0.26719 & $-8.19 * * *$ \\
\hline Role of state & -0.0528 & $-2.63 * * *$ & -0.0528 & $-2.63 * * *$ & -0.0528 & $-2.63 * * *$ \\
\hline Developement & -0.0597 & $-3.43 * * *$ & -0.0597 & $-3.43 * * *$ & -0.0597 & $-3.43 * * *$ \\
\hline CI & -1.69366 & $-1.22 * * *$ & -1.24682 & $-1.34 * * *$ & -1.24 & $-1.34 * * *$ \\
\hline CI*R. Intermediate & - & - & - & - & - & - \\
\hline CI*R. Flexible & 0.44684 & $0.3^{*}$ & - & - & - & - \\
\hline CI*R. Fixe & - & - & -0.446 & $-0.30^{*}$ & -0.4468 & $-0.30^{*}$ \\
\hline Constant & -26.150 & -3.17 & -26.267 & -3.19 & -26.105 & -3.18 \\
\hline Husman Chi2(11) & 31.67 & - & 31.67 & - & 31.67 & - \\
\hline p-value (Prob>Chi2) & 0.0009 & - & 0.0009 & - & 0.0009 & - \\
\hline Random effect chi2(12) & 149.74 & - & 149.74 & - & 149.74 & - \\
\hline p-value (Prob> Chi2) & 0.0000 & - & 0.000 & - & 0.000 & - \\
\hline
\end{tabular}

$(*)$ : significant at $10 \%,(* *)$ : significant at $5 \%,(* * *)$ Significant at $1 \%$ level - numbers in parenthesis matching $\mathrm{P}>|t|$ 
For model (1), the flexible regime act positively on growth by ensuring an $0.0449 \%$ increase per year while the intermediate regime negatively impacts growth. Arguably, the intermediate exchange rate regime is more unfavorable to growth than the floating regime. This invalidates the conclusion of Ghosh and al. (2003) who indicated that the intermediate regimes are more favorable to growth than the floating regime.

Furthermore, we noticed that the binary variable relative to inflation targeting is statistically significant at the $1 \%$ level but it acts negatively on growth.

Most important for us is the coefficient of the interactive variable (inflation targeting (ci) - flexible regime). This is positive and statistically significant at the $10 \%$ level. In other words, the inflation targeting strategy and exchange rate targeting can increase the growth of $0.44684 \%$ per year in the developing countries. Therefore, the countries can combine the two strategies to achieve high growth. Therefore, an inflation targeting strategy is nothing more than an additional adjustment- targeting strategy.

In model (2) which includes both the fixed and the flexible extreme regimes, the released results show that these two polar regimes have a positive and statistically significant effect on growth. In this regard, we note a slight preference given to the flexible regime that can increase growth by $0.1623 \%$ per year while the fixed regime marks a growth increase of $0.11738 \%$ per year. There is a preference for the flexible regime. Thus, one can associate a lower growth under the fixed regime than the flexible one. This finding affirms the idea of several authors including miles, (2007) arguing that the fixed exchange rates are harmful to growth because they lead to an increase in the risk premium on the parallel market.

Our results can be interpreted by the results of Levy-Yeyati and Struzengger, (2001) which concluded that the fixed exchange rate regimes are associated with a low economic growth in the developing countries as these regimes are unable to absorb the shock on the terms of trade.

In this model, inflation targeting remains statistically significant and has a negative impact on growth. It should be noted that even when adding a new variable combined with the fixed regime (CI*RFixe), the statistical effect remains significant but still negative. Thus, a single or combined inflation targeting strategy with a fixed scheme has no effect on growth.

In model (3), the results show that both the fixed and intermediate exchange rate regimes negatively and significantly influence growth. This same conclusion was reached for the effect of the targeting strategy on growth. Indeed, its effect is still negative on growth.

It should be noted that a combination of an inflation- targeting strategy and the fixed regime reduces growth by $0.448 \%$ for the emerging countries. Thus, these countries cannot rely on these two strategies to improve performance including increased growth.

Therefore, we can deduce from the results of the three yielded models that the combination (CI*RFlexible) induced the highest level of growth in our sample. It seems that a flexible regime is an essential complement of an inflation targeting strategy in the emerging countries.

For the control variables, we to state that for the three models, we found that the rate of investment, the role of the state, the accumulation of knowledge and inflation are statistically significant for growth, confirming the signs predicted by the theory. Even so, the physical capital variables, human capital, the degree of financial development and trade openness affect growth in the emerging countries.

\subsubsection{Links between Inflation Targeting, and Inflation Regime Change}

The following table provides the results of the estimation for the case where the dependent variable is inflation.

Table 3. Results of the estimation of the effect of the simultaneous adoption of an inflation targeting strategy and exchange on inflation

\begin{tabular}{lccccc}
\hline \multirow{2}{*}{ Inflation } & \multicolumn{2}{c}{ Intermediate-flexible (model 1) } & \multicolumn{2}{c}{ Fixed -flexible (model 2) } & \multicolumn{2}{c}{ Fixed-intermediate (model 3) } \\
\cline { 2 - 5 } & Coefficient & t-student & Coefficient & t-student & Coefficient \\
\hline Intermediate & -0.1393 & $(-0.47) *$ & - & - & -0.78137 \\
Flexible & 0.642008 & $(4.72) * * *$ & 0.781377 & $2.62 * * *$ & $-2.62 * *$ \\
Fixed & - & - & 0.13936 & $0.47 *$ & - \\
CI & -0.7752 & $-1.59 * * *$ & -1.64009 & $-10.67 * * *$ & -0.62008 \\
Growth rate GDP & -17.66 & $-7.27 * * *$ & -17.66 & $-7.27 * * *$ & -1.64 \\
Openess & -0.00043 & $-0.14 *$ & -0.00043 & $-0.14 *$ & -17.66 \\
\hline
\end{tabular}




\begin{tabular}{|c|c|c|c|c|c|c|}
\hline CI*R. Intermediate & - & - & - & - & - & - \\
\hline CI*R. Flexible & -0.86487 & $-1.76^{* * *}$ & - & - & - & - \\
\hline CI*R. Fixed & - & - & 0.86487 & $1.76^{* * * *}$ & 0.86487 & $1.76^{* * *}$ \\
\hline Constant & 2.1994 & $10.61 * * *$ & 2.06 & $6.69 * *$ & 2.8418 & $13.84 * * *$ \\
\hline Husman Chi2(6) & 29.42 & - & 29.42 & - & 29.42 & - \\
\hline p-value (Prob> Chi2) & 0.0001 & - & 0.0001 & - & 0.0001 & - \\
\hline Random effect chi2(6) & 234.25 & - & 234.25 & - & 234.25 & - \\
\hline p-value (Prob> Chi2) & 0.0000 & - & 0.000 & - & 0.000 & - \\
\hline
\end{tabular}

$(*)$ : significant at $10 \%,(* *)$ : significant at 5\%,(**) Significant at $1 \%$ level - numbers in parenthesis matching P> $|t|$

For model (1), our regression is for the countries adopting the intermediate-flexible regime. The results show that the intermediate exchange rate regime has a negative and statistically significant effect on the level of inflation. Indeed, such a regime can reduce inflation by $0.1393 \%$ per year. However, the flexible exchange rate regime acts significantly and positively on inflation. This scheme increases the inflation rate by $0.642 \%$ per year.

Moreover, our results reveal that the inflation targeting strategy tends to reduce inflation from $0.775 \%$ per year. We noticed that inflation targeting strategy accompanied with a flexible regime can reduce inflation by $0.86487 \%$ per year. Moreover, this is the lowest level in relation to other strategies.

So, again, there is a complementarity between the regime and a flexible inflation targeting strategy which aims to reduce inflation.

For model (2), our results indicate that the flexible regime has a positive and significant effect on the level of inflation. Indeed, we find an increase of $0.78 \%$ in the rate inflation. The same result was found for the fixed plan or it increases inflation by $0.139 \%$ per year. In addition, an inflation targeting strategy allows the emerging countries to reduce their inflation rate by $1.64 \%$ per year.

However, if these countries make use of an inflation targeting strategy with a fixed exchange rate regime, they cannot reduce inflation, but instead they will have an increase in their $0.86487 \%$ inflation rate. So, such a combination is ineffective for inflation.

For model (3), where we integrate the fixed-intermediate exchange rate regime, our empirical results reveal that the two exchange rate regimes have a significant and negative effect on the level of inflation. Indeed, the intermediate regime reduced inflation by $0.7837 \%$ per annum and the fixed exchange rate regime reduced inflation from $0.62008 \%$ per year. Both regimes favorably influence inflation in emerging countries. In addition, the emerging markets may lead to the same result by adopting an inflation targeting strategy. This strategy helps to reduce inflation to $1.64 \%$ per annum. However, a combination of inflation targeting strategy together with a fixed rate increases inflation. In this case, these two strategies are substitutable.

Finally, from the results yielded from three regressions, we can deduce that the most appropriate level of macroeconomic performance in inflation control is provided by an alternative combination of an inflation targeting strategy and a flexible exchange rate regime.

So, it is more relevant to blend inflation targeting with a flexible regime in our sample which guarantees to those countries the lowest inflation level and the highest growth level growth. Thus, a flexible system is a complement of an inflation targeting strategy and not a substitute.

\section{Conclusion}

The aim of this research paper is to figure out whether the simultaneous implementation of an exchange rate regime and a strategy of inflation targeting policy is a complement or substitute for the conduct of an effective monetary policy in terms of increasing the growth level and the reduction of the level of inflation in emerging countries.

Our empirical study involved a sample of 28 emerging market countries in the 1985-2008 period. And we proceeded with two empirical steps; the first is based on the average of the comparison tests for inflation and growth targeting between two groups of and non- inflation targeting countries and adopting various types of exchange rate regime.

The second step is based on a fixed effect- panel model, the dependent variables being the inflation and growth levels and the independent variables are the control vectors, namely the degree of openness to international trade and the growth rate for inflation; the accumulation of knowledge, the stock of physical capital variable, the stock of human capital, the inflation rate, the role of the state and the degree of financial development for growth and the 
dummy variables related to inflation targeting, the exchange rate regime and interactions, which describe the different possible combinations of the strategies undertaken by the latter.

Based on the results yielded from the two empirical steps, it appears that the group of countries targeting the level of inflation and adopting a fixed system shows a relatively low level of growth and relatively high inflation. Thus we deduced, that a combination of an inflation targeting strategy accompanied with fixed rate increases inflation and reduces growth. In this case, these two strategies are substitutable.

Also, we note that the group of countries targeting the level of inflation and at the same time adopting a flexible exchange rate records macroeconomic performance in terms of growth and inflation significantly better than other the countries in the sample of the non-inflation targeting countries and using the same exchange rate flexibility.

It denotes that the adoption of a flexible regime accompanied with an inflation-targeting strategy allows the emerging countries to improve their macroeconomic performance. Therefore, such a finding is that a growing complementary relationship seems to occur between an inflation-targeting strategy and a flexible -exchange rate regime.

In conclusion, we can see that the combination of inflation-targeting and a flexible exchange- rate- regime induces the most appropriate levels of macroeconomic performance in terms of inflation control associated with higher levels of development and growth in our sample. it thus seems that a floating-exchange -rate regime is an essential complement of the inflation targeting policy in emerging countries.

\section{References}

Aizenman, J., Hutchinson, M., \& Noy, I. (2011). Inflation targeting and real exchange rates in emerging markets. World Development, 39(5), 712-724. http://dx.doi.org/10.1016/j.worlddev.2010.11.005

Andersen, T. B., Nikolaj, M. M., \& Jens, N. (2014). Inflation-targeting, flexible exchange rates and macroeconomic performance since the great recession. Retrieved from http://www.ceps.eu

Bernanke, B. S., \& Mishkin, F. S. (1997). Inflation Targeting: a new framework for monetary policy. Journal of Economic Perspectives, 11, 97-116. http://dx.doi.org/10.1257/jep.11.2.97

Edwards, S. (2006). The relationship between exchange rates and inflation targeting revisited. NBER WP 12163, April.

Fisher. (2001). Régimes de taux de change: Le bipolarisme est-il justifié? Finances Et Développement, Juin 2001.

Garcia, C. J., Restrepo, J. E., \& Roger, S. (2011). How much should inflation targeters care about the exchange rate? Journal of International Money and Finance, 30(7), 1590-1617. http://dx.doi.org/10.1016/j.jimonfin.2011.06.017

Gosh, A. R., Glude, A. M., \& Wolf, H. (2003). Exchange rate regimes: Classification and consequences. Presse de mit.

Levy-Yeyati, E., \& Federico, S. (2000b). To float or to trail: evidence on the impact of exchange rate regimes. cif working paper no. 01/2001 (Buenos Aires: Universidad Torcuato Di Tella). Retrieved from http://www.utdt.edu/ ely/growth_final.pdf

Mccallum, B. T. (2006). Singapore's exchange rate-centered monetary policy regime and its relevance for china. Mas staff paper no. 43, Monetary Authority of Singapore.

Miles, W. (2007). Do inflation targeting handcuffs restrain leviathan? Hard pegs vs. inflation targets for fiscal discipline in emerging markets. Applied Economics Letters, 14(9), 647-651. http://dx.doi.org/10.1080/13504850500447448

Mishkin, F. S., \& Klaus, S. H. (2002). One decade of inflation targeting in the world: What do we know? what do we need to know? NBER WP 8397, July.

Mohanty, M. S., \& Klau, M. (2004). Monetary policy rules in emerging market economies: Issues and evidence. Bis working papers no. 149, Bank for International Settlements.

Mohanty, M. S., \& Marc, K. (2005). Monetary policy rules in emerging market economies: Issues and evidence. In R. J. Langhammer, \& L. vinhas de souza (Eds.), monetary policy and macroeconomic stabilization in latin america. http://dx.doi.org/10.1007/3-540-28201-7_13

Ostry, J. D., Ghosh, A., \& Chamon, M. (2012). Two targets, two instruments: Monetary and exchange rate policies in emerging market economies. IMF staff discussion note 12/01, international monetary fund. 
http://dx.doi.org/10.5089/9781475503623.006

Pavasuthipaisit, R. (2010). Should inflation-targeting central banks respond to exchange rate movements? Journal of International Money and Finance, 29(3), 460-485. http://dx.doi.org/10.1016/j.jimonfin.2009.06.005

Pourroy, M. (2012). Does exchange rate control improve inflation targeting in emerging economies? Economics Letters, 116(3), 448-450. http://dx.doi.org/10.1016/j.econlet.2012.04.036

Reinhart, C. M., \& Rogoff, K. S. (2004). The modern history of exchange rate arrangemnts: A reinterpretation. Quarterly Journal of Economics, 119(1), 1-48. http://dx.doi.org/10.1162/003355304772839515

Whelan, K. (2013). A broader mandate: Why inflation targeting is inadequate. In L. Reichlin, \& R. Baldwin (Eds.), Is inflation targeting dead? Centre for economic policy research (CEPR), London.

\section{Notes}

Note 1. The IMF (2006) recorded a number of 16 emerging countries that have simultaneously adopted inflation targeting and targeting exchange rate regime simultaneously.

Note 2. The eight sections are: 1Exchange rate regimes with no separate legal tender, currency unions, dollarization or Eurosation; 2 Currency edge, 3 Fixed anchors against a currency or a Currency basket with a fluctuation margin (+or-1\%), 4 fixed exchange rate at the inner of a fluctuation band; 5, the crowling pegs, anchors with central parities adjusted each time according to the pre-announced fixed rules based on as of quantitative indicators; 6 , the crowling bands, crowling pegs with strips of + or $-1 \%$; 7 the managed float, operation without commitment to a target pre-announced a path for the exchange rate, free; 8 flutter whose exchange rate is determined by the market (free float).

Note 3. Average growth of the countries targeted for the period from the date of adoption of inflation targeting until 2008 and for the period 2000 to 2008 for countries not targeted.

Note 4 . The average inflation of targeting countries for the period from the date of adoption of inflation targeting until 2008 and for the period 2000 to 2008 for countries not targeted.

\section{Copyrights}

Copyright for this article is retained by the author(s), with first publication rights granted to the journal.

This is an open-access article distributed under the terms and conditions of the Creative Commons Attribution license (http://creativecommons.org/licenses/by/3.0/). 